\title{
Counselling parents in child behaviour therapy
}

\author{
R McAuley
}

This is the third of a series of articles on treatment of child psychiatric disorders.

Over the past 21 years the field of behaviour therapy with children has expanded considerably. Ollendick cites a 1968 report by Gelfand and Hartman in which only 70 studies relating to child and adolescent behaviour therapy could be found in the literature. ${ }^{1}$ By 1981 this figure had expanded to 1000 . This growth has continued and so much so that it is now difficult for the practising clinician to keep abreast of developments within the now extensive literature.

In the late 1960s behaviour therapy was characterised by two main approaches. Directly from the principles of operant conditioning, reinforcement procedures were developed for increasing and decreasing behaviour and these found favour mostly in the fields of mental handicap and conduct disorders. The other approach derived its strategies from classical or respondent conditioning and, in the main, included desensitisation techniques and these were used most often to treat children with phobic and emotional disorders.

In the 1970s interest in imitation learning expanded the behaviour therapist's repertoire through the development of a new set of procedures collectively referred to as 'social skills training'. Finally, the late 1970s and 1980s saw the development of a set of techniques deriving from an interest in cognitive processes. Included among these are self control techniques, self instructional training, coping and problem solving strategies, and approaches for the reversal of dysfunctional thinking. Though these latter procedures have seen use with wide groups of child problems, they have not, as yet, been satisfactorily validated in their use with overt clinical disorders.

One thread running right through the development of child behaviour therapy has been the idea that therapists, rather than treating the problems exhibited by children, should educate the parents into this role. Inherently, this makes good sense as it is the parents who have the maximum 'therapeutic' contact with their children. The approach, which is often referred to as 'parent training', has enjoyed enormous success and attention, and especially so in the fields of conduct disorder and mental handicap. Traditionally, hallmarks of this approach include: (i) careful family assessment through interviews and observations of parent-child interactions: (ii) training parents to monitor and track child behaviour; (iii) educating parents in reinforcement principles and a range of allied techniques, such as differential reinforcement, time out, contingency contracting and how to use point incentive systems; and, finally, (iv) teaching parents to generalise their successes across behaviours and over time. In this paper the author examines some of the issues relevant to each of these steps but, in particular, discusses aspects pertinent to the busy clinicians in routine practice.

When consulted about child behaviour problems, such as tantrums, sleep difficulties, disobedience and aggressiveness, it is often tempting to jump quickly to advice about firm, consistent management. However, between complaint and successful resolution, several aspects of our approach will influence the likelihood of success. Firstly, our methods of assessment and consequent understanding of the individuals, interactions, and developmental issues may suggest factors other than the actual consequences, which also require therapeutic attention. Secondly, as therapists the way in which we interact with the family will in many instances influence the treatment outcome. Thirdly, the manner in which treatment techniques are imparted will affect their utilisation, and finally, experience in the sorts of 'road blocks' that may hinder treatment progress will be important. Some aspects of each of these issues is discussed below.

\section{Assessment of child behaviour problems}

A basic prerequisite to any treatment advice is an understanding of the behavioural problems, their antecedents, and consequences.

\section{BEHAVIOURAL ANTECEDENTS}

Traditionally, parent trainers have concerned themselves with what is observable, and through this have demonstrated a number of immediate and frequently occurring problem antecedents. These include vague instructions, frequently repeated instructions, inconsistency in approach to the behaviour, failure to attend to prosocial behaviour, and attention to disruptive behaviour and sequences typified by escalating anger and aggression. ${ }^{2}$ The ramifications for treatment obviously include teaching the parent to observe more accurately, issue clearer and fewer instructions, and to act earlier and more efficiency. However, this focus on immediate antecedents is often only part of the story. 
The immediate interaction between parent and child is influenced by a wide range of events, including other interactions, the effects of family and environmental stressors, and the attitudes and beliefs that parents hold about child behaviour. Failure to attend to these will at worst result in unsuccessful treatment. On the other hand, careful consideration may suggest other and more appropriate approaches to treatment. Some of these aspects are discussed further.

Marital problems may lead to serious disagreements about child management, less time for the child, and impose additional stress upon the child. ${ }^{3}$ In the face of open conflict, child management advice is ill advised until such difficulties are resolved or resolving. Perhaps though, in dysfunctional marriages characterised by apathy and disinterest, advice to one parent may have beneficial effects. Problems between parents may also be expressed in more covert ways. For instance, the child who sleeps with a parent may serve to mask parental sexual difficulties. One way to test such a hypothesis is to question parents about the consequences for them of successful child problem management. Other family interactional influences may present more subtly, and only became appreciated through careful investigation. Grandparents, for instance, may criticise and undermine parental efforts. This can often be managed either by appropriate parental assertion, ignoring, or at worst by grandparent exclusion. Finally, siblings who while not perceived as problematic, nevertheless often exhibit some problems and therefore may require to be included in treatment. ${ }^{2}$ More subtly, if labelled 'good', such children may, in maintaining their relative position, persist in covertly provoking the labelled child. In such cases, if intersibling fighting is problematic, then parents may be best advised to ignore fighting in order to avoid being dragged into a 'good'/'bad' labelling game.

Families may be exposed to a range of stressors that have detrimental effects on child rearing. It has been established that in the year or so after parental separation, mothers may have management difficulties especially with their sons. ${ }^{4}$ Here, rather than focusing intervention on child management, it may be far more appropriate to support and advise the mother with regard to the enormous adjustment she is having to make. Other stresses, such as parental depression, illness, or child illness, also require appropriate consideration before child management advice is contemplated.

An inquiry into parent day to day coping may reveal ways in which child difficulties can indirectly be alleviated. At the simplest level for instance, adjustments in parents' daily timetable can create more space and thus reduce stress around areas of child management. For example, in one of the author's cases, a young mother habitually attempted to dress three young children, make breakfast, get them out to school, and complete some household tasks_-all in the space of one hour. In situations where organisation is more chaotic, then various problem solving and coping skills strategies may be required.
Multiproblem families pose the greatest challenge for parent trainers. Not only are they multistressed, but also they frequently exhibit a broad range of poor coping skills. Also it is often assumed that they are deficient in parenting skills. However, this is not usually the complete story. Research has demonstrated that these parents can 'learn' and successfully use behavioural management techniques, but unfortunately such improvements are often not maintained. ${ }^{5}$ It would appear that their problems lie more within dysfunctional attributions and expectations about their children and their life circumstances. In any case, efforts to improve child management in such families will at least require prolonged and diverse treatment.

In the early days of parent training an implicit assumption that attitude change would follow behaviour change existed. This was a naive generalisation. At initial interviews, one is often struck by the strength of parental belief statements such as, 'I've tried everything and nothing works', 'He's just like his father', 'He doesn't learn', etc. No doubt, in milder cases, direct behavioural advice with successful application may extinguish these beliefs. However, in more difficult cases the belief may hinder progress from the beginning. Take for example, a mother who feels that nothing works, thinks she is a bad parent, and sees her child as failing to learn, and consider how she approaches her child when trying to get him to bed. She is likely to feel fed up and/or angry, and in consequence her approaches to the child will often convey a lack of belief in her own management ability. Frequent failure will reinforce such dysfunctional beliefs, and perhaps also lead to inconsistency of effort and rule application. Also, other adults may reinforce the beliefs either by taking over the management, or more directly, by criticising the mother. If the therapist is to avoid failure, then some preliminary work with dysfunctional beliefs will often be necessary. Basically, such will involve identifying the beliefs, teaching the parent to monitor them, then learning to examine them according to reality and finally, in consequence, learning to establish more appropriate ones in their place. For example, if the parent considers that 'nothing works', then an in-depth examination of behavioural incidents to which this is linked is required. Often this will reveal that what was thought not to work, was not in the first instance applied appropriately. Equally, other behavioural incidents will illustrate that the techniques appropriately applied did work. In cases where dysfunctional thinking is intense and associated with significant emotional distress, then treatment lasting many sessions may be required. First the dysfunctional thinking will need modifying, next relaxation training and coping strategies may be required for the emotional components, and finally, problem solving approaches may be advocated in order to substitute more appropriate and constructive thinking. Such approaches have shown some promise in a number of difficult areas, such as child abuse. ${ }^{6}$

When significant child behaviour problems, parent dysfunctional thinking, and emotional 
problems coexist, then it is likely that family rules governing child behaviour may become loose and inconsistently applied. It is of course difficult to track behaviour when the general rules are unclear. As already hinted, it is therefore important in early therapy to spend time discussing rules. For instance, what are the absolute 'don'ts' (for example, no throwing things around, no verbal abuse to parents, etc), what behaviour is expected at mealtimes, homework times, and so on.

One very important area of parent thinking centres on expectations about child behaviour. Are the expectations of the child, given his or her particular developmental level, appropriate? The child abuse literature frequently refers to the inappropriate expectations that such parents have of their children. ${ }^{7}$ For instance, they may expect the child to exhibit high levels of self control at very young ages, or they might expect their baby. to respond exclusively to them without being able to appreciate the need for interactional sensitivity and flexibility. Some years ago the author treated an 18 month old child who presented with a six month history of persistent crying. Being behaviourally orientated, an interactional understanding of the problem was sought in terms of attention versus non-attention. Within this framework the results of a prolonged observation failed to produce answers. However, when concepts such as maternal sensitivity to the child were considered, the nature of the problem became clear. Observation showed that the mother was attending to the child indiscriminantly in the sense that she failed to respond to social cues emitted by the child. Some simple parent coaching on such issues produced a dramatic resolution within 24 hours! Thus behavioural assessments in general are incomplete unless the parents' complaints of the child behaviour are seen within the context of normal child development. In some cases then, it may be the parents' expectations which require modification and not the child's behaviour.

An early exploration of parent expectations about treatment and about the future is also often useful. Understanding what they expect from the treatment may reveal useful information about motivation. Generally parents pushed into therapy by outside agencies may view such negatively and as unhelpful. If this can be addressed early on, then it may be possible to bring about a more positive attitude to therapy. An exploration of the future may be beneficial in two ways. Firstly looking at what may happen if the problems persist may help generate further motivation to attempt change now. Secondly looking at the future ramifications of positive change for the child and parent may not only help motivation, but may also suggest future actions that might solidify change. For instance, given positive changes, what will you and your child be able to do in the future that you can't do now?

THE PROBLEM BEHAVIOUR

Ask a number of people to define what they mean by child tantrums, and you will find that the definitions vary considerably from person to person. Such a simple test clearly illustrates the importance of gathering very specific information about the occurrence of the problem behaviour, its frequency, and where it occurs. This becomes even more important when parental complaints are vague. For instance, with complaints such as, 'she is anxious', one would want clear episodic data about what she does, says, and what emotions are expressed. Information of this type may reveal that the parents' concerns about the problem are justified, or that their perception of the behaviour is in some way erroneous. For instance, depressed parents often perceive child behaviour as more problematic than it is, ${ }^{8}$ or multidistressed parents may exhibit inappropriately high standards when making judgments about child behaviour. ${ }^{7}$ Clearly, such findings have ramifications for the treatment focus. In other instances information may reveal that the parents have not actually observed the problem of interest and typical examples of this include intersibling fighting as already discussed. Finally, accurate descriptions of the behaviour will, where appropriate, facilitate the therapist in making judgments about what opposite prosocial behaviour might later be reinforced.

\section{BEHAVIOURAL CONSEQUENCES}

Knowledge of the consequences of problem behaviour will obviously increase our understanding about why the problems persist. Interest in consequences will, in most instances, focus upon exactly what they are, how frequently they occur, how appropriate they are, and how consistently they are applied. Spreading the inquiry into common positive and negative consequences employed by the parent will also hint at what ones may, with or without modification, be utilised later. Finally, information on the relative density of negative or positive ones will be important as this too may require later therapeutic consideration. To illustrate: research in families with aggressive children has shown that often parents use a preponderance of negative to positive consequences. $^{2}$

Previous reference was made to the parent belief that nothing works. In such cases, careful inquiry into what rewards and punishments they consider don't work may actually reveal that these techniques (as the parents see them) have paradoxical effects. In other words, when the smack is applied the child behaviour worsens, or when the parent praises, the appropriate behaviour decreases. Clearly, in these cases the techniques are not being employed at sufficient intensity or their timing is inappropriate. In treatment, appropriate corrections or other consequences will need to be found.

There is a frequent tendency in therapists to consider immediate consequences and to ignore ones occurring more distantly. For example, when a mother gives in to a child's refusal to go to school, the child ceases his distress and the mother's giving in is reinforced. However, later we may find the child watching television and enjoying his mother's company. Here the child 
receives further and later reinforcement (sometimes referred to as secondary gain) for his refusal behaviour. Such important consequential arrangements require attention and can only be addressed if we proceed in our exploration of the problems with questions such as, 'and then what happened next'.

\section{Assessment methods}

Parent trainers have employed a range of assessment techniques and these have included interviews, direct observation, various questionnaires, and parent records. Here the focus of attention is on interviews and parent records.

A perusal of many texts on parent training written over five to 10 years ago reveals an overwhelming preoccupation with observational methods of assessment. No doubt this resulted considerably from an interest in achieving objectivity. Also, much of the parent training development occurred within research settings, where the luxury of careful and painstaking observation of interaction was feasible. Clinicians in the service sector are frequently unable to spare such time, and therefore, must rely on methods that are less time consuming. Fortunately, in recent years, parent trainers have for a number of reasons shown an increased interest in interviewing. ${ }^{9}$ Firstly the recognition that events not readily observable, such as parental disputes and what they thought, are important has resulted in more attention. Secondly, the realisation that success is not only about observable changes, but also about changes in beliefs and attitudes (which are less immediately observable) has been influential in shaping assessment methods.

Research into interviewing methods has clearly demonstrated that it is possible to obtain high quality factual information about family life, without necessarily hindering the important development of the therapist/client relationship (see later). ${ }^{10}$ This author would go further and state (on the basis of teaching experience), that many therapists do not realise that interviewers can gain clear interactional information. Practically speaking, a careful inquiry into recent behavioural episodes, sequence by sequence, can be achieved if the interviewer adopts an attitude that he would like to be able to visualise the episode in the manner of a video recording. Obviously, while such interviewing skills can never completely override the potential value of observing events, for the service clinician they can function satisfactorily as a major assessment method.

Parent observational records of behavioural episodes serve several purposes. Further information about the problem is gained, the parents' attention is focused more specifically on the problems, and finally in consequence they can begin to observe more accurately as was mentioned earlier. Unfortunately, clinical experience indicates that parents are poor at keeping detailed records-and this is despite careful instruction and training. On visits to the clinic it is often readily apparent that their records lack detail or were completed shortly before the appointment. One can improve this by telephone checks between appointments, or by asking for audio recordings of episodes made at home, and finally the therapist can use the scanty records as a starting point for further focused interviewing as already discussed.

\section{Some thoughts on treatment}

Careful assessment will in most instances suggest the most appropriate treatment techniques. Such will include ensuring that the situations are maximally conducive to behaviour change through encouraging clear rules, ensuring time is available to manage the problems, optimising the parents' general approach, and coaching in the use of a variety of techniques such as positive reinforcement, differential attention, time out, and point or star systems. Some discussion has already taken place with regard to things that might be changed in order to increase the probability of appropriate behaviour. The specific techniques of change are not discussed here. Rather, in this section some general and important issues relating to their application are examined.

\section{THERAPIST SKILLS}

A number of research reports over the past 15 years have drawn attention to the importance of therapist skills in bringing about positive change. For instance, Alexander et al, in working with delinquent families, demonstrated that a therapist's ability not only to empathise accurately, but also to direct families clearly, contributed significantly to the likelihood of successful outcome. ${ }^{11}$ Wahler and Dumas, in treating multiproblem families, have drawn attention to the importance of adopting a friendly, non-coercive style. ${ }^{5}$ Finally, Patterson and colleagues (cited in Twardosz and Nordquist) have begun to examine therapist skills mainly as a consequence of inconsistent results in some of their parent training programmes. ${ }^{12}$ Obviously the requisite therapist skills will vary from case to case. In those where problems are mild and parents highly motivated, straightforward direct quickly given advice may be sufficient. However, in more difficult cases, the therapist will often need to create an atmosphere in which the client feels acknowledged, supported, and encouraged to consider the resolution of their problems in a positive light. Early directing and teaching may simply drive some of these parents away. In the end, failure to give credence to the importance of therapist skills will result in resistance in therapy and possible subsequent treatment failure.

\section{LEARNING THERAPY TECHNIOUES}

Popular books such as Toddler Taming contain much sound practical advice that could benefit many of the parents seen at busy outpatient clinics. ${ }^{13}$ However, and unfortunately, many seem unable to transfer the information into action. Clearly, the distance between the written word and successful application is vast, and also such material frequently fails to address the individualistic nature of parent-child difficulties. 
How then can parents best learn to effectively apply behavioural techniques?

A number of studies have demonstrated that parents learn most effectively when techniques are role played or rehearsed and least well when the knowledge is imparted didactically. ${ }^{14}$ The former teaching methods are time consuming, and thus in busy clinical practice one has to find some kind of reasonable balance. One possible solution is to train small groups of six to seven parents. This has been done and would appear superficially to address the time problem. ${ }^{15}$ Additionally, working with parents in groups can in itself be facilitative, because it offers a forum in which parents can discuss and communicate their problems and solutions. Unfortunately, arranging convening and administering group sessions can be costly in terms of time, and this is something that is often inadequately addressed in the literature. Another approach is to employ prepared film and video demonstrations. ${ }^{12}$ Though this has received some attention, this author would suggest that it has not been explored in this country to its full potential. Overall, one could argue that further research is required into each of these different training methods. However, the reality probably is that the different training methods are each in their own ways effective, but that their use needs to be matched carefully to the varying needs of different clinical samples.

\section{ANTICIPATING ROADBLOCKS IN TREATMENT}

As has been indicated, careful assessment should hint that at the optimal treatment approach and thus help reduce problems that might occur in therapy. However, there are a number of commonly recurring themes within treatment which are worth addressing.

Many parents do not readily appreciate that behavioural change in themselves and child is time consuming, and that in consequence (as is the case with learning any new skill) space and time requires to be created. For instance, in attempting to help a child develop homework skills, it is advisable as far as is possible to ensure that other household tasks occurring at the specified time take a secondary role. In all behavioural management applications it is important to discuss this with the parents with a view to encouraging maximum effort and, in consequence, reduce the negative influence of other competing events.

Secondly, standard techniques and approaches will never suit all parents. For instance, some parents might prefer to use a bedroom for time out and others prefer a kitchen corner. Similarly, when managing disruptive mealtime behaviour, some parents may have no difficulty in removing food until the next mealtime, but others may be unwilling to go this far. In all cases, therefore, the treatment techniques require to be presented, discussed, and then tailored to suit individual needs. Throughout such discourse one of the therapist's functions will be to ensure that what is being applied fulfills the therapeutic requirements, for example, that the positive reinforcement really is reinforcing to the child.
Thirdly, parents require to be made aware that the behavioural problems may, in early treatment, increase and intensify before they improve. This is important as some parents may read the worsening as a sign, that the techniques are not working, or worse still are damaging their child. Once this point is understood then parents may hopefully read the worsening signs with encouragement and thus muster further effort.

Fourthly, experience teaches us of some of the manipulative craft which children can exhibit during behavioural programmes. For instance, the child may adopt an, 'I don't care attitude', or may elicit parental guilt through statements such as, 'you don't love me', 'you're cruel to me', etc. Viewed from a distance, the manipulative repertoires of some children can be both creative and amusing. Parents often require to be warned.

Finally, throughout treatment therapists require continually to hold the question, 'I wonder what might prevent successful application', at the back of their minds. For example, how do we manage interfering adults, the presence of siblings, and the fact that parental tiredness may create difficulties in managing problems in the middle of the night.

\section{COURSE OF TREATMENT}

If one is to modify successfully parent-child behaviour, then contact requires to be quite frequent. There is little use in initially seeing parents and children on a monthly basis. Not only do parents require frequent encouragement and support, but also they require help with early teething problems, and some of these have been referred to in the sections immediately above. At first sight, this may appear time consuming, however much of this early work can be conducted by telephone. In fact, in many milder cases treatment may work very well with one or two clinic visits and the remainder of contact made by telephone. Once treatment has begun to succeed, then follow up at less frequent intervals is advisable for up to one year, as research findings have demonstrated that many families require booster treatment throughout this period. ${ }^{2}$

\section{EFFECTIVENESS OF TREATMENT}

Both clinical experience and research have shown that training parents to manage their children's behavioural problems is effective. The treatment approach would appear to work best when problems are mild, are of the acting out type, are of short duration, and where the general family background is shown to be relatively stable. Conversely, when problems are extensive, have been present for years, and occur in a context of multiple other problems, then treatments show little in the way of durable effects. ${ }^{16}$ Of those cases that fall between these two extremes, the question of success is much more difficult to answer.

The issue of determining success rates is further compounded by a host of variables that include the specific types of problems, the 
duration and intensity of the therapy, the quality of therapy (for example, were the therapists experienced or just newly trained), and finally what it is that actually constituted success. With regard to the latter point a number of issues arise. Many single case studies and reports concentrate on reductions in difficult behaviour, and neglect whether or not the child shows significant increases in prosocial skills, generalisations of changes across environments and relationships, and changes in internal states such as might be reflected in measures of self esteem. Equally, success must be allied to how parents think, perceive, and view the situation as in the first instance they have often been responsible for the referral.

Perhaps it is unrealistic to expect much more at this time. After all the social learning theories underpinning parent training are still largely hypothetical, and secondly, our knowledge of how family events such as marital problems effect and interact with the individual child over time is still largely in its infancy. Finally, there is a feeling that much of the literature's use of the word success is synonymous with cure. Kendall quite rightly asserts that the notion that people can be 'fixed' is unreasonable and unhelpful. ${ }^{17}$ For instance, if our successfully treated school refuser returns with further problems three years later, this is not necessarily indicative of past failure, but rather indicates that more therapy is required. The conclusion we can draw is that if we can be helpful at one moment in time then our function becomes more realistic, credible, and healthy.

\section{Concluding remarks}

This brief examination of parent training in behavioural child management has focused only on some aspects considered important by a practising clinician. Many areas have not even been considered. These, among others, include observational methodology, common treatment techniques such as time out and differential attention, contingency contracting procedures, coping and problem solving strategies, and a range of adjunctive treatment procedures designed to improve and enhance outcome. For further information the reader is referred to a number of useful source books listed in the appendix.

The majority of developments in parent training have taken place in research settings, and while such development continues there is an urgent need to conduct efficacy studies in the routine clinical sector in order to establish how the technology will stand up when time is short and caseloads are large. Hopefully, the new emphasis on medical and clinical audit will serve as well in this direction over the next decade and beyond.

1 Ollendick TH. Child and adolescent behaviour therapy. In: Garfield JL, Bergin AE, eds. Handbook of psychotherapy and behavior change. New York: Wiley, 1986: 525-64.

2 Patterson GR, Reid JB, Jones RR, Couger RE. A social learning approach to family interventions: families with aggressive children. Eugene Oregon: Castalia, 1975.

3 Jenkins JM, Smith MA. Marital disharmony and children's behaviour problems: aspects of a poor marriage that affect children adversely. F Child Psychol Psychiatry 1991;32: 793-810.
4 Wallerstein J, Corbin SB, Lewis JM. Children of divorce: a ten-year study. In: Hetherington EM, Arasteh J, eds. Impact of divorce, single parenting and step-parenting on children. Hillsdale, New Jersey: Erlbaum, 1989: 202-14.

5 Wahler RG, Dumas JE. Changing the observational coding styles of insular and noninsular mothers: a step towards maintenance of parent training effects. In: Dangel RF,
Polster RA, eds. Parent training: foundations of research and Polster RA, eds. Parent training: foundations of

6 Wolfe DA. Child abuse. In: Hersen M, Hasselt VB, eds. Behavior therapy with children and adolescents. New York: Behavior therapy with chil
Wiley, 1987: $385-415$.

7 Wolfe DA. Child abuse. London: Sage, 1987.

8 Webster-Stratton C, Hammond M. Maternal depression and its relationship to life stress, perceptions and child behavior problems, parenting behaviors, and child conduct problems. F Abnorm Child Psychol 1988;16:299-315.

9 Mash EJ, Terdal LG. Behavioral assessment of child and family disturbance. In: Mash EJ, Terdal LG, eds. Behaviour assessment of childhood disorders. New York: Guilford, 1988: 3-65.

$10 \operatorname{Cox}$ A, Rutter M. Diagnostic appraisal and interviewing. In: Rutter M, Hersov L, eds. Child and adolescent psychiatry: modern approaches. Oxford: Blackwell, 1985: 233-48.

11 Alexander JF, Barton C, Schiavo RS, Parsons BV. Systems behavioral intervention with families of delinquents: therapist characteristics, family behavior and outcome. therapist characteristics, family behavior

12 Twardosz S, Nordquist VM. Parent training. In: Hersen $M$ Van Hasselt VB, eds. Behavior therapy with children and adolescents. New York: John Wiley, 1987.

13 Green C. Toddler taming. London: Doubleday, 1990.

14 O'Dell SL, O'Quin JA, Alford BA, O'Briant AL, Bradlyn AS, Giebenhain JC. Predicting the acquisition of parenting skills via four training methods. Behavior Therapy 1982 13:194-208.

15 O'Dell SL. Progress in parent training. In: Hersen M, Eisler RM, Miller PM, eds. Progress behavior modification. New York: Academic Press, 1985: 57-108.

16 Wahler RG, Graves MG. Setting events in social networks: ally or enemy in child behavior therapy. Behavior Therapy 1983;14:19-36.

17 Kendall PC. The generalization and maintenance of behavior change: comments, considerations, and the 'no-cure' criticism. Behavior Therapy 1989;20:357-64.

\section{Appendix}

The child behaviour therapy books listed are ones that the author has found most useful. This list is by no means exhaustive, but should provide readers with a fairly broad coverage of the field of child behaviour therapy.

\section{CHILD BEHAVIOUR ASSESSMENT}

The one text listed here, which is now in its second edition, is authoratative and has become a standard bench book. In addition to chapters on conduct, emotional and developmental problems, there are also ones on brain injury, chronic pain, obesity, anorexia nervosa, eneuresis, encopresis, child abuse, and others. The breadth of coverage has hitherto been unusual in behaviourally oriented textbooks.

1 Mash EJ, Terdal LG, eds. Behavioral assessment of childhood disorders. New York: Guilford, 1988.

\section{THERAPIST HANDBOOKS}

The two books here provide therapists with detailed guidelines for conducting child behaviour therapy assessment, treatment planning, treatment implementation, and outcome evaluation. Both texts are practical and contain a wealth of clinical experience.

\footnotetext{
1 Herbert M. Behavioural treatment of problem children. London: Academic Press, 1981

2 Herbert M. Working with children and their families. London: Routledge, 1988.
}

CHILD BEHAVIOUR THERAPY HANDBOOKS

The two books listed deal with a wide range of 
different childhood disorders and problems. The author prefers the second text, mainly because of its masterly coverage of vast areas of behaviour therapy literature. Unfortunately this text is now rapidly becoming rather dated. 1 Hersen M, Van Hasselt VB, eds. Behavior therapy with
children and adolescents. New York: Wiley, 1987.

Ross AO. Child behavior therapy: principles, procedures and empirical basis. New York: Wiley, 1981.

CHILD BEHAVIOURAL MANAGEMENT MANUALS

The three books listed provide basic information on the management of a range of child behavioural problems. Generally they are fairly straightforward and not too laden with technical jargon. The author prefers the first book, as not only does it contain much about practical management advice, but also it addresses many of the practical problems encountered in counselling parents.

1 Barkely RA. Defiant children. New York: Guilford, 1990.

2 Green C. Toddler taming. London: Doubleday, 1990.

3 Patterson GR. Families. Champaign, Illinois: Research Press, 1977. 